\title{
REFLEXOS DIRETOS DA CONSTITUIÇÃO FEDERAL DE 1988 COMO LEGISLAÇÃO SIMBÓLICA NOS DIREITOS À EDUCAÇÃO E AO TRABALHO
}

\author{
Vanessa Vieira Pessanha ${ }^{1}$
}

RESUMO: O presente trabalho tem como objetivo primordial demonstrar de que maneira a ação de criar e/ou modificar leis pode funcionar como um ato simbólico, especialmente no que tange aos direitos à educação e ao trabalho. A relevância do tema diz respeito à promoção de reflexões sobre o processo de produção e interpretação das normas, passos fundamentais para o estudo da Hermenêutica Jurídica, bem como de aplicação de dispositivos legais. Trata-se de uma pesquisa qualitativa, com método de revisão bibliográfica, que almeja reforçar a percepção do coeficiente de simbologia presente, em especial, na Constituição Federal de 1988.

PALAVRAS-CHAVE: Legislação simbólica; Constituição Federal de 1988; Hermenêutica Jurídica; Direito à Educação; Direito ao Trabalho.

\section{DIRECT REFLECTIONS OF THE 1988 FEDERAL CONSTITUTION AS SYMBOLIC LEGISLATION ON THE RIGHTS TO EDUCATION AND WORK}

\begin{abstract}
The main purpose of this paper is to demonstrate how the act of creating and / or modifying laws can function as a symbolic act, especially with regard to the rights to education and work. The relevance of the topic is to promote reflection on the process of production and interpretation of norms, fundamental steps for the study of legal hermeneutics, as well as application of legal provisions. It is a qualitative research, with method of bibliographical revision, which aims to reinforce the perception of the coefficient of symbology present, especially, in the Federal Constitution of 1988.
\end{abstract}

KEYWORDS: Symbolic legislation; Federal Constitution of 1988; Legal Hermeneutics; Right to Education; Right to Work.

\footnotetext{
${ }^{1}$ Doutora em Relações Sociais e Novos Direitos pela Universidade Federal da Bahia (UFBA), Mestre em Direito Privado e Econômico pela UFBA, Especialista em Direito e Processo do Trabalho pela Faculdade Baiana de Direito, Bacharela em Direito pela Universidade Salvador (UNIFACS), Bacharela e Licenciada em Letras Vernáculas pela UFBA. Professora concursada para as cadeiras de Direito do Trabalho e Direito Processual do Trabalho da Universidade do Estado da Bahia (UNEB). Pesquisadora com enfoque nas áreas de Direitos Sociais e Direito do Trabalho. Líder do grupo de pesquisa "Relações de Trabalho, Globalização e Direitos Fundamentais" (UNEB) e vinculada ao grupo de pesquisa "Relações de Trabalho na Contemporaneidade" (UFBA). Membro do Instituto Baiano de Direito do Trabalho (IBDT). Contato: vanessapessanha@ymail.com
} 


\section{REFLEXOS DIRETOS DA CONSTITUIÇÃO FEDERAL DE 1988 COMO LEGISLAÇÃO SIMBÓLICA NOS DIREITOS À EDUCAÇÃO E AO TRABALHO}

1 INTRODUÇÃO

O presente artigo corresponde a uma pesquisa qualitativa, com método de revisão bibliográfica, cuja abordagem pretende analisar a presença da ideia de legislação simbólica - em especial, no que se refere à Constituição Federal de 1988 - no sistema jurídico brasileiro, estabelecendo um diálogo direto com dois direitos sociais de grande relevância para os indivíduos: a educação e o trabalho.

Em um contexto de ponderação analítica e de adequação hermenêutica, o Direito deve ser pensado mais densamente sobre três bases fundamentais: sua criação, interpretação e aplicação.

O tema da legislação simbólica surge especialmente em função de uma realidade de pouco cumprimento de algumas normas que compõem o ordenamento jurídico, como ocorre em território brasileiro. Trata-se de um assunto intrigante, pois é sabido que as normas existem, porém sua aplicabilidade, quando ocorre, deixa a desejar, gerando na população a sensação de inoperância do Direito. Resta evidenciada, dessa maneira, a relevância do tema e, como consequência direta, sua justificativa, ressaltando a necessidade de compreensão da ciência jurídica, que deve estar voltada à concretização adequada dos direitos.

Como forma de observar e construir a percepção acerca da legislação simbólica no ordenamento jurídico pátrio, foram escolhidos os direitos fundamentais à educação e ao trabalho, sobretudo pelo enquadramento na perspectiva de direitos sociais por excelência e, como tal, de aplicabilidade e eficácia bastante discutidas.

Dentro desse horizonte, a proposta inicial é conhecer brevemente algumas questões que envolvem a legislação simbólica para, em seguida, ter acesso a algumas linhas acerca dos referidos direitos fundamentais (com suas peculiaridades e nuances).

Na sequência, são apresentadas demonstrações de legislação simbólica diretamente relacionadas aos referidos direitos, com vistas a refletir sobre o processo legislativo, a visão hermenêutica e, especialmente, sobre a necessidade de efetivação desses direitos, sob pena de nunca ocorrer a evolução social que tanto é almejada.

Segue, agora, um breve relato acerca da ideia fundante do artigo que ora se apresenta. 


\section{BREVES LINHAS ACERCA DA IDEIA DE LEGISLAÇÃO SIMBÓLICA}

Os símbolos fazem parte da vida em sociedade. Diariamente, a convivência com símbolos faz-se presente de tal modo que, muitas vezes, sequer são percebidos de maneira consciente.

E a simbologia, longe de se aprisionar aos estudos de Semiótica e Semiologia, tem espaço em diversas áreas do conhecimento, como ocorre com o Direito e, mais especificamente, com o processo de criação e alteração de leis.

A legislação simbólica pode ser compreendida como o principal efeito da perda de eficácia social da norma jurídica. Ocorre, assim, uma anomia jurídica, pois a norma deixa de existir como norma.

No entendimento de Marcelo Neves (2011), autor que trata da constitucionalização simbólica especificamente, o ponto chave do tema diz respeito a um crescimento substancial da força simbólica atinente à norma constitucional, ao passo que a força de concretude é deixada em segundo plano.

Vale registrar, contudo, que os ensinamentos são passíveis de aplicação para outras legislações, especialmente tendo em vista o caráter de não aplicabilidade, perceptível em outros instrumentos normativos.

Assim sendo, faz-se salutar compreender também que não só a legislação pode ser considerada simbólica, mas também um outro estágio jurídico, que é a produção do direito como um todo, alcançando, dessa maneira, também a jurisprudência, as políticas públicas, as portarias etc. Essa situação pode gerar consequências ainda mais graves, uma vez que dizem respeito também à aplicação do direito.

Paulo Bezerra (2001) evoca questões fundamentais para o entendimento desse ponto, a exemplo da representação social que o legislador tem do eleitor e que o eleitor tem do legislador - fator que diz muito da forma como o processo legislativo costuma ser conduzido e da maneira como o cidadão lida com as questões que envolvem o Poder Legislativo. Ainda nesse sentido, outro ponto relevante levantado pelo referido autor é de que o direito não é dado, e sim construído (ou seja, é uma ciência cultural).

Vale citar também Michel Miaille (2005), para quem o direito não passa de uma representação da ideologia dominante. Por meio dessa afirmação, muito do que se conhece 


\section{REFLEXOS DIRETOS DA CONSTITUIÇÃO FEDERAL DE 1988 COMO LEGISLAÇÃO SIMBÓLICA NOS DIREITOS À EDUCAÇÃO E AO TRABALHO}

como legislação simbólica passa a fazer sentido, tendo em vista a necessidade de manutenção do status quo.

Resgatando Pierre Bourdieu (2006) e a noção de poder simbólico, é inegável, para além da perspectiva concreta, o poder simbólico que a ciência jurídica exerce nos indivíduos, sendo esse um elemento de grande valor para a própria existência do Direito.

Outra viés interessante é apontado por Paulo Bezerra, Raquel Bezerra e Tagore Trajano (2012) na observância da legislação simbólica em situações nas quais há uma dissociação entre o direito e a realidade social.

Nesse sentido, a legislação simbólica existe basicamente para atender a três realidades: confirmação de valores sociais, demonstração da capacidade de ação do Estado para resolver problemas (traz uma sensação de bem estar social, mas não gera o efeito buscado legislação álibi) e transferência do conflito de um momento atual para um momento futuro (uma vez que não resolverá o problema).

Essas ideias serão melhor exploradas em cotejo com alguns dispositivos legais no item 4 do presente artigo.

Ver-se-ão, nesse momento, algumas questões acerca dos direitos fundamentais à educação e ao trabalho.

\section{DIREITOS FUNDAMENTAIS À EDUCAÇÃO E AO TRABALHO}

Os direitos à educação e ao trabalho serão apresentados na sequência, com o intuito de conhecer seu alcance e relevância dentro do rol de direitos fundamentais sociais.

\subsection{DIREITO À EDUCAÇÃO}

Para iniciar o tópico, faz-se necessário conceituar o processo educacional. Maria Cristina de Brito Lima (2003, p. 01-02, grifos do autor) explica que a educação 
[...] é a prática contínua e intermitente de se transmitir e receber informações, que se vão construindo com o tempo, por elas sendo o homem influenciado, ao tempo que também as influencia, ajudando, assim, a desenvolver o meio onde vive e, também, desenvolver-se.

A educação é concebida como um direito fundamental no art. $6^{\circ}$ da Constituição Federal de 1988 e, ao ser atribuído ao processo educacional tal status jurídico, estudiosos do tema - a exemplo de Wilson Donizeti Liberati (2004, p. 210) - fazem questão de registrar que se trata de um direito destinado a todos os indivíduos.

Como lembra Murillo José Digiácomo (2004, p. 277), “mais do que um direito fundamental de toda criança e adolescente, [...] o direito à educação se constitui num verdadeiro direito natural inerente à pessoa humana, sejam quais forem sua idade ou sua condição social”.

Dessa forma, compreender a educação como um instrumento de transformação social passa pela ideia inicial de entendê-la como estágio essencial na vida do indivíduo, preparando, inclusive, seu processo de formação como cidadão.

Nas palavras de Wilson Donizeti Liberati (2004, p. 210), a partir de tal acepção é possível compreender a frase “educação é poder”, “permitindo concluir que ela é a chave para estabelecer e reforçar a Democracia, promover o desenvolvimento humano sustentável e contribuir para uma paz baseada no respeito mútuo e na justiça social”.

Inventariar a educação como instrumento que potencializa o desenvolvimento pessoal (indivíduo) e de toda a sociedade ao seu redor representa uma das maneiras de vislumbrar sua relevância.

Visão interessante é também apresentada por Regina Maria Fonseca Muniz (2002, p. 9), ao asseverar que “a educação engloba a instrução, mas é muito mais ampla. Sua finalidade é tornar os homens mais íntegros, a fim de que possam usar da técnica que receberam com sabedoria [...]”.

Na passagem citada, a autora demonstra uma perspectiva mais humanística da educação, como um fator de evolução, de transformação do indivíduo, capaz não apenas de absorver conhecimentos, mas também de modificar o mundo ao seu redor por meio de uma atuação adequada e ética.

Ismael Gílio (2000, p. 37) trata da ligação nitidamente existente entre a educação e a economia:

A educação, [...] à medida que se buscam soluções tanto para problemas sociais brasileiros quanto para a inserção da economia brasileira no 


\section{REFLEXOS DIRETOS DA CONSTITUIÇÃO FEDERAL DE 1988 COMO LEGISLAÇÃO SIMBÓLICA NOS DIREITOS À EDUCAÇÃO E AO TRABALHO}

mercado internacional, ou para a construção de um novo ciclo ou modelo de desenvolvimento, apresenta-se como a principal e mais importante estratégia, pois está indissoluvelmente ligada ao processo de desenvolvimento econômico. A importância da educação em nenhuma época foi tão grande como agora.

É muito difícil, de fato, compreender o processo de desenvolvimento econômico e social sem o devido investimento em educação, ou seja, sem que as pessoas possam ter acesso à escola - e nela possam permanecer durante o tempo necessário à obtenção da finalidade almejada -, buscando a oportunidade de desenvolvimento e consolidação das bases para alçar voos, alcançando uma melhor condição de vida e, em última análise, construindo um espaço social mais igualitário.

Tratando, ainda, da realidade brasileira, Adelaide Alves Dias (2007, p. 448) apresenta um retrato da situação vivenciada atualmente:

Não obstante, tenhamos avançado, a partir da segunda metade do Século XX, em termos de definição da educação como direito do homem, a educação como direito está longe de ser efetivada em termos de direito de toda e qualquer pessoa em nosso país. A legitimidade e o reconhecimento do direito humano à educação têm sido objeto de longos debates e acirradas disputas no campo político, social e educacional, advindos da luta pela democratização da educação pública, em termos de acesso, permanência e qualidade da educação.

A título de provocação final acerca da relevância da educação, vale trazer à baila a seguinte afirmação: “onde a liderança, a criatividade e o conhecimento desempenham um papel cada vez mais preponderante, o direito à educação se constitui, em última analise, no direito a participar da vida do mundo moderno” (LIBERATI, 2004, p. 210).

As oportunidades, na conjuntura atual, são, inegavelmente, cada vez mais pautadas na preparação apropriada do indivíduo para os objetivos que deseja alcançar, tornando, assim, o processo educacional cada vez mais basilar.

Observa-se, assim, nessas breves considerações, como a doutrina já está bastante consolidada no sentido de compreender a amplitude e o alcance do referido direito social, referendando todo o discurso jurídico de relevância e impossibilidade de pensar em melhorias de natureza social sem o devido investimento em sua concretização.

Uma vez oferecidas noções sobre a educação, tratar-se-á, a partir desse momento, do direito fundamental ao trabalho. 


\subsection{DIREITO AO TRABALHO}

O trabalho, enquanto valor social, corresponde a um dos fundamentos da República Federativa do Brasil, sendo citado desde o primeiro artigo (inciso IV) da Constituição Federal de 1988.

A Constituição Federal Portuguesa registra claramente o direito ao trabalho em seu art. 58. ${ }^{\circ}$, de abrangência que merece menção. Trata-se de um dispositivo legal que contempla, inclusive, não só a afirmação de que se trata de um direito, mas também afirma que é um direito de todos e elenca os deveres do Estado no sentido de efetivá-lo: promoção de políticas de pleno emprego; igualdade de oportunidades no que diz respeito à escolha da profissão, dando possibilidade de acesso a quaisquer tipos de cargos; formação cultural e técnica; valorização dos trabalhadores (PORTUGAL, 1976).

Os elementos citados constituem, sem dúvida, frentes de aplicabilidade do direito ao trabalho, sendo de extrema relevância para compreender seu alcance e a necessidade de sua efetivação.

O art. $6^{\circ}$ da CF/88 - o mesmo que apresenta o fundamento constitucional do direito à educação - é responsável por oferecer nominalmente a lista de direitos sociais, dentre os quais se encontra também o direito ao trabalho.

Para Luz Pacheco Zerga (2007, p. 43-45), a centralidade do trabalho na vida humana e sua direta relação com a dignidade e o desenvolvimento da personalidade servem como pilares para a construção do ordenamento. O entendimento social, ao qualificar o trabalho como privilégio, dever e vocação da pessoa, destaca manifestamente que, apesar de ser uma obrigação, é um direito, que tem a categoria adicional de privilégio e vocação - tratando-se, portanto, de um direito fundamental com particularidades.

É possível afirmar que o trabalho constitui uma das facetas da dignidade humana e, como tal, merece destaque no panorama dos estudos jurídicos, especialmente levando em consideração seu caráter de subsistência e realização do indivíduo.

Tendo em vista a sua relevância, Maria Hemília Fonseca (2006, p. 149-150) oferece, também, o entendimento de que o direito ao trabalho pode ser pensado como um direito 


\section{REFLEXOS DIRETOS DA CONSTITUIÇÃO FEDERAL DE 1988 COMO LEGISLAÇÃO SIMBÓLICA NOS DIREITOS À EDUCAÇÃO E AO TRABALHO}

de liberdade, notadamente nos Estados em que não há previsão expressa na Carta Magna - ou seja, mesmo os Estados que não apresentem o direito em comento elencado legalmente poderiam utilizar esse caminho para assegurar sua existência e aplicabilidade. Ressalte-se, contudo, que esse não é o caso do Brasil, uma vez que possui o registro do referido direito, conforme já mencionado.

Maria Áurea Cecato (2007), a respeito dos aspectos financeiro (subsistência) e moral (valor social do trabalho), assevera:

o trabalho é um dos direitos essenciais. Sua supressão significa também supressão de dignidade. Em primeiro lugar, porque o salário dele resultante é o instrumento de acesso às condições materiais indispensáveis a uma vida digna. Em segundo, porque a sua ausência gera sentimento de diminuição moral e repercute na inserção social do trabalhador, visto que se tem disseminada a cultura do trabalho como valor social e ético.

Trabalho e dignidade são associados, de maneira recorrente, notadamente pela análise do trabalho como um fator de complemento da vida humana, seja pela necessidade de manter a si e à família, seja pelo valor social atribuído ao processo de labor.

Dessa forma, o direito ao trabalho pode ser considerado um direito da maior importância no cenário social, entretanto com questionamentos intrínsecos que muito preocupam os estudiosos da área, a exemplo de Fábio Rodrigues Gomes (2008, p. 67, grifos do autor):

[...] mesmo que atingíssemos um consenso quanto à fundamentalidade material do direito ao trabalho, o que deveríamos entender como sendo exigível a partir desse direito? Como devemos interpretar o direito ao trabalho, de modo a torná-lo mais que um mero símbolo? Como transformá-lo num direito efetivo?

Esse corresponde a um dos grandes problemas enfrentados pelo direito ao trabalho: promover sua efetivação, deixando de ser apenas uma utopia (embora muito desejada) e passando a se concretizar, até mesmo como uma das formas de implementar efetivamente o bem estar social.

Leonardo Vieira Wandelli (2012) compartilha os problemas oriundos da ausência de efetividade de um direito fundamental tão importante em qualquer ordenamento jurídico: 
[...] há um claro déficit de efetividade desse direito e que começa já pela escassa referência que encontramos a respeito tanto nos livros de direito constitucional e de direito do trabalho quanto na jurisprudência do STF ou do TST. Sua centralidade normativa é inquestionável, mas seu baixo desenvolvimento científico e sua inaplicação prática são tão evidentes quanto. Considero que, para enfrentar essa inefetividade exemplar, é preciso repensar, antes, a fundamentação do direito ao trabalho, de modo a tornar mais visíveis as diversas dimensões do seu conteúdo. É certo que o Estado não pode garantir um posto de trabalho a todos. Mas o conteúdo do nosso direito não se esgota aí. Ele deve atuar com toda a inteireza da relevância concreta do trabalho para a dignidade humana; tanto daqueles que, precisando, não têm um trabalho, quanto daqueles que têm um trabalho, assalariado ou não.

Delimitar a zona de alcance e os caminhos de atuação, de fato, consiste em um passo indispensável no sentido de lutar pela concretização do direito ao trabalho. Um exemplo interessante é o dispositivo da Constituição Portuguesa, já citado anteriormente, deixando registradas as questões contempladas pelo dispositivo legal, no intuito de que seja possível afiançar o cumprimento do referido direito, uma vez que se sabe, com maior precisão, o que se espera da materialização do direito em observância.

Torna-se oportuno citar Benizete de Medeiros (2008, p. 100): “talvez um dos grandes desafios e perigos da economia globalizada é instalar na sociedade e no trabalhador, em especial, uma sorte indefinida, uma vida de incertezas [...]”.

Essas incertezas, sem dúvida, coadunam com a ideia de fundamentalidade do direito ao trabalho, especialmente por ser o trabalho, na maioria das vezes, a fonte de sustento do indivíduo, elemento que lhe garante, portanto, subsídios para viver com dignidade.

Uma vez que estão postos os alicerces do presente artigo, o item seguinte desenvolver-se-á com o fulcro de estabelecer ilações entre esses alicerces, procurando entender algumas situações socialmente perceptíveis relacionadas à ideia de legislação simbólica.

\section{REFLEXOS DIRETOS DA CONSTITUIÇÃO FEDERAL DE 1988 COMO LEGISLAÇÃO SIMBÓLICA NOS DIREITOS À EDUCAÇÃO E AO TRABALHO}




\section{REFLEXOS DIRETOS DA CONSTITUIÇÃO FEDERAL DE 1988 COMO LEGISLAÇÃO SIMBÓLICA NOS DIREITOS À EDUCAÇÃO E AO TRABALHO}

É notória a constatação de que a Constituição Federal de 1988 está repleta de normas que existem apenas na previsão legal (sem aplicabilidade prática) e essa realidade atinge diretamente os direitos à educação e ao trabalho.

A lição de Paulo Bezerra (2007b, p. 60) é fundamental nesse contexto: “os direitos fundamentais não reconhecidos e inseridos nos textos legais como abstrações ou para serem aplicados em situações excepcionais, mas, em grande parte, é isso que tem ocorrido”.

O grande número de obras destinadas a demonstrar e defender a eficácia dos direitos sociais constitui prova bastante eloquente acerca da simbologia que envolve os direitos fundamentais sociais.

Como lembra Ana Cristina Costa Meireles (2008, p. 229), os obstáculos vão desde os custos que são inerentes à materialização desses direitos (noção bastante difundida da reserva do possível) até à ausência de políticas públicas do Estado assegurar os direitos dessa natureza.

Faz-se indispensável registrar, contudo, o estudo dos autores Stephan Holmes e Cass R. Sunstein (1999), no qual fica corroborada a não obrigatoriedade de relacionar direitos sociais necessariamente a custos, além de registrar que direitos prestacionais não são uma exclusividade dos direitos de segunda dimensão, grupo ou família.

E com o objetivo de demonstrar que nem o discurso de direitos positivos ou prestacionais invalida a obrigatoriedade de materialização dos referidos direitos, Ingo Wolfgang Sarlet (2015, p. 289) registra que “[...] mesmo os direitos fundamentais a prestações são inequivocamente autênticos direitos fundamentais, constituindo (justamente em razão disto) direito imediatamente aplicável, nos termos do disposto no art. $5^{\circ}, \S 1^{\circ}$, de nossa Constituição”.

Outra percepção interesse é a de que, em que pese a tentativa de difusão de fundamentos jurídicos louváveis, a exemplo do princípio do não retrocesso social, sabe-se que, infelizmente, situações prejudiciais a posteriori ocorrem com certa frequência, momentos nos quais novamente é percebido o simbolismo que envolve diretamente a ciência jurídica.

Nas palavras de Luiz Fernando Calil de Freitas (2007, p. 192-193):

A noção de supremacia da Constituição, considerada conjuntamente com a compreensão segundo a qual a experiência jurídica permite vislumbrar ao menos as duas vertentes antes referidas, tem como decorrência lógica a ideia de que a aposição de limites e restrições aos direitos fundamentais é limitada, redundando na constatação da 
existência de um dever jurídico de proteção ao núcleo essencial dos direitos fundamentais.

Ainda no que tange à existência de normas sem verificação na verdade real dos fatos, vale dirigir-se à observação e análise de alguns dispositivos da Constituição Federal de 1988 mais diretamente relacionados aos direitos à educação e ao trabalho.

Um exemplo bastante eloquente a ser citado é o art. 206 da Constituição Federal de 1988, responsável por apresentar um elenco de princípios relacionados ao que se almeja como modelo de ensino a ser aplicado:

Art. 206. O ensino será ministrado com base nos seguintes princípios:

I - igualdade de condições para o acesso e permanência na escola;

II - liberdade de aprender, ensinar, pesquisar e divulgar o pensamento, a arte e o saber;

III - pluralismo de idéias e de concepções pedagógicas, e coexistência de instituições públicas e privadas de ensino;

IV - gratuidade do ensino público em estabelecimentos oficiais;

V - valorização dos profissionais da educação escolar, garantidos, na forma da lei, planos de carreira, com ingresso exclusivamente por concurso público de provas e títulos, aos das redes públicas;

VI - gestão democrática do ensino público, na forma da lei;

VII - garantia de padrão de qualidade.

VIII - piso salarial profissional nacional para os profissionais da educação escolar pública, nos termos de lei federal.

Muitas palavras-chave e expressões, de significativo impacto social, são utilizadas no trecho citado, valendo o registro de algumas delas: igualdade de condições, acesso e permanência, valorização dos profissionais da educação escolar, garantia de padrão de qualidade, dentre outras.

Sabe-se, contudo, que a materialização desses princípios - de fato, muito importantes para que se tenha um cenário educacional mais digno e democrático - é uma situação que não corresponde à realidade brasileira. Dessa forma, a legislação pode ser classificada como sem aplicação prática em muitos dos seus principais aspectos, caracterizando o simbolismo de suas previsões.

Todas as questões previstas no dispositivo mencionado são de grande relevância social, porém, justamente por isso, sendo apenas regra posta e não cumprida, esvazia seu sentido, tornando sua existência restrita ao mundo do dever ser e, assim sendo, permite apenas que se verifique a existência de uma norma, mas que dela não se extraia resultado. 


\section{REFLEXOS DIRETOS DA CONSTITUIÇÃO FEDERAL DE 1988 COMO LEGISLAÇÃO SIMBÓLICA NOS DIREITOS À EDUCAÇÃO E AO TRABALHO}

A relevância do direito à educação, em especial, é registrada por Paulo Bezerra (2007a, p. 185): “[...] sendo os direitos culturais verdadeiros direitos de identidade, a educação, em sua dimensão de ensino, deve servir de base de multiplicação e de transmissão de valores constituintes dessa mesma identidade”.

Nos dizeres de Cármen Lúcia Antunes Rocha (2008, p. 151), “a cultura é instrumento de libertação. [...] desoprime onde havia opressão, liberta onde havia escravidão, socializa onde antes havia individualização".

Percebe-se, assim, a necessidade da demanda, a profundidade de seus benefícios e as mazelas pela não concretização desta.

O art. 208 da CF/88 - em que estão registrados os deveres do Estado no que diz respeito à educação -, por sua vez, segue a mesma linha de simbolismo apresentada pelo art. 206:

Art. 208. O dever do Estado com a educação será efetivado mediante a garantia de:

I - ensino fundamental, obrigatório e gratuito, assegurada, inclusive, sua oferta gratuita para todos os que a ele não tiveram acesso na idade própria;

II - progressiva universalização do ensino médio gratuito;

III - atendimento educacional especializado aos portadores de deficiência, preferencialmente na rede regular de ensino;

IV - educação infantil, em creche e pré-escola, às crianças até 5 (cinco) anos de idade;

V - acesso aos níveis mais elevados do ensino, da pesquisa e da criação artística, segundo a capacidade de cada um;

VI - oferta de ensino noturno regular, adequado às condições do educando;

VII - atendimento ao educando, no ensino fundamental, através de programas suplementares de material didático-escolar, transporte, alimentação e assistência à saúde.

$\S 1^{\circ}$ - O acesso ao ensino obrigatório e gratuito é direito público subjetivo.

$\S 2^{\circ}$ - O não-oferecimento do ensino obrigatório pelo Poder Público, ou sua oferta irregular, importa responsabilidade da autoridade competente.

$\S 3^{\circ}$ - Compete ao Poder Público recensear os educandos no ensino fundamental, fazer-lhes a chamada e zelar, junto aos pais ou responsáveis, pela freqüência à escola.

Apesar de um maior grau de concretude desse dispositivo em comparação ao art. 206, percebe-se, ainda, uma série de questões bastante sérias e sem materialização efetiva, a exemplo do inciso VII do art. 208, quando se pensa no cenário habitual de precariedade do programa de transporte para a escola (quando há).

Outra norma que merece ser citada é o art. 214 da CF/88: 
Art. 214. A lei estabelecerá o plano nacional de educação, de duração plurianual, visando à articulação e ao desenvolvimento do ensino em seus diversos níveis e à integração das ações do Poder Público que conduzam à:

I - erradicação do analfabetismo;

II - universalização do atendimento escolar;

III - melhoria da qualidade do ensino;

IV - formação para o trabalho;

V - promoção humanística, científica e tecnológica do País.

Mais uma vez surgem temas que, pode-se afirmar, costumam ser vistos como verdadeiros “clamores populares”, a exemplo da melhoria da qualidade de ensino e da formação para o trabalho.

Vale a pena direcionar a análise, nesse momento, para o direito ao trabalho.

Conforme registrado no item 3.2, o trabalho, enquanto valor social, é um dos fundamentos da República Federativa do Brasil, sendo citado desde o primeiro artigo (inciso IV) da Constituição Federal.

No inciso XIII do art. $5^{\circ}$ da CF/88, é apresentada a garantia de liberdade para exercer qualquer trabalho, ressalvando o legislador as profissões que demandam qualificações específicas.

É notória, contudo, a realidade maciça de trabalhadores que não podem exercer, de fato, uma liberdade material de escolha, tendo em vista a impossibilidade de acesso a uma qualificação que os permita alcançar esse nível de liberdade.

Da mesma maneira, uma política de pleno emprego prevista na Constituição Federal de 1988 (art. 170, VIII) soará sempre como legislação simbólica enquanto não sejam verificadas, na prática, verdadeiras medidas de melhoria dos empregos formais.

O trabalho está caracterizado, no caput do art. $6^{\circ}$, como um direito social (juntamente com o direito à educação, dentre outros) e, no art. $7^{\circ}$, é pormenorizado em seus incisos, que tratam de diversos temas conexos, a exemplo da previsão expressa de remunerar melhor o trabalho noturno em comparação ao diurno (art. $7^{\circ}$, inciso IX).

A disposição geral do Título VIII (Da Ordem Social) é objetiva no que tange à influência do trabalho: “art. 193. A ordem social tem como base o primado do trabalho, e como objetivo o bem-estar e a justiça sociais” (BRASIL, 1988).

Na perspectiva da criança e do adolescente, o tema é tratado no art. 227, só que $\S 3^{\circ}$, incisos I a III, estabelecendo como idade mínima para começar a trabalhar quatorze anos, garantindo os direitos previdenciários e trabalhistas, bem como o acesso do trabalhador adolescente à escola. 


\section{REFLEXOS DIRETOS DA CONSTITUIÇÃO FEDERAL DE 1988 COMO LEGISLAÇÃO SIMBÓLICA NOS DIREITOS À EDUCAÇÃO E AO TRABALHO}

Observando-se o cenário trabalhista, contudo, sabe-se que a erradicação do trabalho infantil ainda está longe de ser uma realidade visualizada no Brasil.

Como afirma Paulo Bezerra (2007b, p. 58), “[...] o mero reconhecimento da previsão legal, mesmo que constitucional, é insuficiente para uma realidade mais concreta dos direitos fundamentais”.

O referido autor afirma, ainda, que são políticas públicas sérias que resolverão os problemas, e não a criação de leis.

No entendimento de Castanheira Neves (2003), vivemos hoje em um mundo de muita lei e pouco direito. Essa assertiva encerra consigo demandas das mais diversas naturezas, sem dúvida colocando a ciência jurídica em ponto de discussão crucial.

Em sintonia com o momento atual e dialogando diretamente com a temática da não aplicabilidade efetiva das leis, Marcos Sampaio (2013, p. 239) afirma que:

Parece pouco, num Estado que não se desvinculou totalmente do sistema de privilégios onde a extrema riqueza convive com a extrema miséria e no qual ainda não se implementou nem sequer o dever de fundamentação das decisões judiciais, ou mesmo a razoável duração dos processos judiciais em curso, que a previsibilidade da atividade jurisdicional possa ser oferecida a partir de um acompanhamento cotidiano e crítico da própria atividade jurisdicional.

Nessa senda de ideias, a constatação da aplicabilidade da percepção de normas que tratam de direitos tão relevantes como o direito à educação e ao trabalho na condição de legislação simbólica remete ao reforço da necessidade premente de enfrentamento dessa realidade em terras brasileiras, a fim de que seja possível verificar uma mudança de paradigmas e uma efetivação das normas simbólicas. Eis o grande desafio.

\section{CONSIDERAÇÕES FINAIS}

Diante de tudo quanto exposto, restou caracterizada a presença da legislação simbólica no contexto dos direitos à educação e ao trabalho, especialmente no que diz respeito às normas de natureza constitucional relacionadas ao tema, elencadas ao longo do presente artigo. 
A legislação simbólica, sem dúvida, pode cumprir papéis na sociedade - como o de mostrar que o Estado está respondendo a um clamor social -, porém, quando é algo que suplanta a efetiva aplicação, passa a ser elemento que necessita de análise e mudança.

O direito à educação e o direito ao trabalho, em virtude de sua relevância social, merecem especial atenção no cenário jurídico. O problema reside, contudo, no fato de se perceber que esse cuidado diferenciado, por vezes, só consegue ser vislumbrado na letra fria da lei, como uma maneira de mostrar à população que há registro formal acerca do padrão que se deseja alcançar.

Dessa forma, em que pese a relevância dos processos de criação e interpretação das normas, percebe-se o quão vital é a etapa de concretização, especialmente em uma sociedade que sente, diariamente, os efeitos da não efetividade. A hermenêutica, nesse contexto, exerce papel inquestionável, sendo alicerce necessário ao desenvolvimento de um discurso que sustente, sem margem para dúvidas, a materialização dos referidos direitos, promovendo interpretação consistente e cada vez mais pacífica nesse sentido.

O reconhecimento da Constituição Federal de 1988 como legislação simbólica nos direitos à educação e ao trabalho deve trazer consigo a consciência da necessidade de transformação, auxiliando na alteração desse cenário em benefício real para os destinatários das normas jurídicas.

Continuar visualizando esses direitos apenas em dizeres indispensáveis previstos na lei - ainda que essa lei seja a Carta Magna do país - não mais deve ser considerado suficiente no meio jurídico, assim como não o é para uma parte significativa da população. E talvez seja esse o princípio da mudança que precisa ocorrer, de forma que as leis passem a não ser mais paradigma único e inaplicável, mas sim prenúncio - no sentido de algo que antecede de fato de aplicabilidade prática efetiva.

\section{REFERÊNCIAS}

BEZERRA, Paulo César Santos. Acesso à justiça: um problema ético-social no plano da realização do direito. Rio de Janeiro: Renovar, 2001.

BEZERRA, Paulo César Santos; BEZERRA, Raquel Tiago; TRAJANO, Tagore. Legislação simbólica: sobre os riscos de manipulação ideológica do direito. Salvador: Editora 2 de Julho, 2012. 


\section{REFLEXOS DIRETOS DA CONSTITUIÇÃO FEDERAL DE 1988 COMO LEGISLAÇÃO SIMBÓLICA NOS DIREITOS À EDUCAÇÃO E AO TRABALHO}

BEZERRA, Paulo Cesar Santos. O ensino jurídico à luz do direito fundamental à educação: em busca de uma prática emancipatória. In: BEZERRA, Paulo Cesar Santos. Temas atuais de direitos fundamentais. 2. ed. Ilhéus: Editus, 2007a.

BEZERRA, Paulo Cesar Santos. Os mecanismos de proteção dos direitos fundamentais: sobre a insuficiência do reconhecimento e da previsão legal e a necessidade de mais efetividade. In: BEZERRA, Paulo Cesar Santos. Temas atuais de direitos fundamentais. 2. ed. Ilhéus: Editus, 2007b.

BOURDIEU, Pierre. O poder simbólico. Trad. Fernando Tomaz. 14. ed. Rio de Janeiro: Bertrand Brasil, 2006.

CECATO, Maria Áurea Baroni. Direito humanos do trabalhador: para além do paradigma da declaração de 1998 da O.I.T. p. 351-371. In: SILVEIRA, Maria Godoy et. al. Educação em Direitos Humanos: fundamentos teórico-metodológicos. João Pessoa: Editora Universitária, 2007.

DIAS, Adelaide Alves. Da educação como direito humano aos direitos humanos como princípio educativo. p. 441-456. In: SILVEIRA, Maria Godoy et. al. Educação em Direitos Humanos: fundamentos teórico-metodológicos. João Pessoa: Editora Universitária, 2007.

DIGIÁCOMO, Murillo José. Instrumentos jurídicos para garantia do direito à educação. In: LIBERATI, Wilson Donizeti. Direito à educação: uma questão de justiça. São Paulo: Malheiros, 2004.

FONSECA, Maria Hemília. Direito ao trabalho: um direito fundamental no ordenamento jurídico brasileiro. 2006. Tese (Doutorado em Direito) - Pontifícia Universidade Católica de São Paulo.

FREITAS, Luiz Fernando Calil de. Direitos fundamentais: limites e restrições. Porto Alegre: Livraria do Advogado, 2007.

GÍLIO, Ismael. Trabalho e educação: formação profissional e mercado de trabalho. São Paulo: Nobel, 2000.

GOMES, Fábio Rodrigues. O direito fundamental ao trabalho: perspectivas histórica, filosófica e dogmático-analítica. Rio de Janeiro: Lumen Juris, 2008.

HOLMES, Stephen; SUNSTEIN, Cass R. The cost of rights: why liberty depends on taxes. New York: W. W. Norton \& Company, 1999.

LIBERATI, Wilson Donizeti. Conteúdo material do direito à educação escolar. p. 207-271. In: LIBERATI, Wilson Donizeti. Direito à educação: uma questão de justiça. São Paulo: Malheiros, 2004.

LIMA, Maria Cristina de Brito. A educação como direito fundamental. Rio de Janeiro: Lumen Juris, 2003. 
MEDEIROS, Benizete Ramos de. Trabalho com dignidade: educação e qualificação é um caminho? São Paulo: LTr, 2008.

MEIRELES, Ana Cristina Costa. A eficácia dos direitos sociais: os direitos subjetivos em face das normas programáticas de direitos sociais. Salvador: JusPodivm, 2008.

MIAILLE, Michel. Introdução crítica ao Direito. 3. ed. São Paulo: Estampa, 2005.

MUNIZ, Regina Maria Fonseca. O direito à educação. Rio de Janeiro: Renovar, 2002.

NEVES, Antonio Castanheira. O actual problema metodológico da interpretação jurídica. Coimbra: Coimbra Editora, 2003.

NEVES, Marcelo. A constitucionalização simbólica. 3. ed. São Paulo: Saraiva, 2011.

PORTUGAL. Constituição da República Portuguesa. 1976. Disponível em:

$<$ http://www.parlamento.pt/Legislacao/paginas/constituicaorepublicaportuguesa.aspx>. Acesso em: 02 abr. 2018.

ROCHA, Cármen Lúcia Antunes. Direito de para todos. 2. ed. Belo Horizonte: Fórum, 2008.

SAMPAIO, Marcos. O conteúdo essencial dos direitos sociais. São Paulo: Saraiva, 2013.

SARLET, Ingo Wolfgang. A eficácia dos direitos fundamentais: uma teoria dos direitos fundamentais na perspectiva constitucional. 12. ed. rev. atual e ampl. Porto Alegre: Livraria do Advogado Editora, 2015.

WANDELLI, Leonardo Vieira. O direito humano e fundamental ao trabalho. Gazeta do Povo, 2012. Disponível em: <http://www.gazetadopovo.com.br/vidapublica/justicadireito/artigos/conteudo.phtml?id=1327330\&tit=O-direito-humano-e-fundamental-aotrabalho>. Acesso em: 28 mar. 2018.

ZERGA, Luz Pacheco. La dignidad humana en el derecho del trabajo. Cizur Menor (Navarra): Thomson/Civitas, 2007. 